\title{
COMPARISON OF POLLEN PRODUCTION AND QUALITY CHARACTERISTICS OF CULTIVATED AND WILD ALMOND SPECIES
}

\author{
Safder Bayazit ${ }^{1 *}$, Oguzhan Çalişkan ${ }^{1}$, and Burhanettin Imrak ${ }^{2}$
}

There are several wild almond species in Turkey included Amygdalus orientalis (Mill.), Amygdalus turcomanica (Lincz.), Amygdalus fenzliana (Fritsch) Lipsky, Amygdalus trichamygdalus (Hand.-Mazz.) Woronow, Amygdalus arabica (Olivier), and Amygdalus webbii (Spach). These species offer a great value for the almond improvement; we studied the pollen viability, germination ratio and pollen yield for seven genotypes of A. orientalis, seven genotypes of A. turcomanica all growing under natural conditions in Southeastern Anatolia (Gaziantep and Şanlıurfa provinces, Turkey). Almond cultivars (Prunus dulcis [Mill.] D.A. Webb) obtained from Pozantı Agricultural Experimental Station, Çukurova University, were also used in the experiment. The pollen viabilities of various almond genotypes were determined by 2,3,5-triphenyltetrazolium chloride (TTC) and fluorescein diacetate (FDA) tests. At the end, pollen germination ratios were established according to Petri dishes method in vitro conditions (1\% agar $+0,10,15$ and $20 \%$ sucrose) while pollen yield was estimated with hemacytometric methods. The results indicated that pollen viability ratios were close to each other in both methods for the genotypes A. orientalis and A.turcomanica. Pollen germination ratios were found to be dependent on the sucrose content as well as on the genotypes used. The pollen of almond cultivars showed similar germination ratios in all of the sucrose concentrations while those pollens of A. orientalis and A. turcomanica genotypes displayed higher germination ratios in $10 \%$ sucrose. The number of anthers in one flower was higher in cultivars whereas the number of pollen grains was lower in other almond species. While the number of pollen grains in one flower was relatively high in A. orientalis genotypes, pollen quality was high in all the three species under research. The results suggested that these two species, namely A. orientalis and A.turcomanica could be employed for future almond breeding programs.

Key words: Amygdalus orientalis, Amygdalus turcomanica, Prunus dulcis, pollen, germination.

$\mathrm{T}^{\mathrm{s}}$ he cultivated almond (Prunus dulcis [Mill.] D.A. Webb) belongs to Rosaceae family, subfamily Prunoideae, and typified by a drupe fruit structure (Kester and Gradziel, 1996). The origin of almonds is middle and west Asia and extends to the China, India, northern Iran, Syria, and Mediterranean countries. Almond is a typical Mediterranean tree, sensitive to cold temperatures, and not tolerant to heavy rainfall. Thus, it is grown only in restricted areas of the world (Kester et al., 1990; Küden, 1997).

Wild populations of almond species representing a wide range of morphological and geographical forms have evolved throughout southwest and central Asia from Turkey and Syria into the Caucasus Mountains, through Iran, and into the deserts of Tian-Shan and Hindu Kush Mountains of Tajikistan, Uzbekistan, and Afghanistan (Kester et al., 1990; Browicz and Zohary, 1996). More than 30 species have been described by botanists may

${ }^{1}$ University of Mustafa Kemal, Faculty of Agriculture, 31034 Antakya, Hatay, Turkey. "Corresponding author (sbayazit30@gmail.com).

${ }^{2}$ University of Çukurova, Faculty of Agriculture, 01120 Adana, Turkey. Received: 16 March 2011.

Accepted: 9 September 2011 represent subspecies or ecotypes within a broad collection of genotypes which are adapted to a range of ecological niches in the deserts, steppes, and mountains of central Asia (Kester and Gradziel, 1996).

Several almond species such as A. orientalis (Mill.), A. turcomanica (Lincz.), A. fenzliana (Fritsch) Lipsky, A. trichamygdalus (Hand.-Mazz.) Woronow, A. arabica (Olivier), and A. webbii (Spach) are found in Anatolia. Some of these species has been partly domesticated and they might offer some possibilities for horticultural utilization. For example, Kester and Gradziel (1996) reported that immense possibilities exist for rootstock improvement through the use of other almond species either by direct selection within the species or by their hybridization with almond cultivars. Thus, these species are important germplasm sources of almond and their wide genetic diversity present among related almond species provides an enlarged pool of available germplasm that has not been sufficiently exploited.

There is not any important restriction regarding hybridization and backcrossing of species in almond breeding studies involving the species present in Anatolia. Successful almond production under different ecological region and conditions requires breeding of resistant 
individuals. For these purposes; A. davidiana (Carr.) and A. mira Koehne are used for disease resistance of peach and self-fertile cultivars of almond, A. orientalis is used for cold resistance and self-fertile cultivar breeding of almond, A. bucharica Korschinsky is used self fertile cultivars of almond, cold resistance breeding of cultivars and crown development control of almond, A. kuramica Korschinsky is used for development of self-fertile types and breeding disease resistance of almond, A. webbii (Spach) is used for breeding self-fertile cultivars and crown development control of almond, P. dulcis is also used in breeding and development of disease and insect resistance of new peach cultivars (Denisov, 1988; Kester et al., 1990; Kester and Gradziel, 1996; Gradziel et al., 2001).

Among the wild almond species of Turkey, A. orientalis is present at the Central and Southeast Anatolia Regions, while A. turcomanica is present in Southeast Anatolia Region. High lime content along with very low yearly precipitation (around $340 \mathrm{~mm}$ ) is typical for Southeast Anatolia Region. Being present under these conditions suggest that these species might be tolerant against unfavorable soil conditions such as lime, rocky soil and drought (Bayazit and Küden, 2007). The plants of $A$. orientalis present under Central Anatolia Region had an average plant height of $151 \mathrm{~cm}$ while they had an average of $238 \mathrm{~cm}$ plant height under and Southeast Anatolia Region (Bayazit and Küden, 2007). These averages suggest that this is a relatively short species and might have a potential for a dwarfing rootstock. Indeed, Atlı (2008) reported that A. orientalis can be utilized as a rootstock for cultivated almond without any incompatibility problem. The researchers also reported that while 'Nonpareil' grafted on 'Texas' gave an accumulative yield of $83.8 \mathrm{~kg}$ at the end of the 4-yr period, 'Nonpareil' grafted on A. orientalis gave 351.1 $\mathrm{kg}$ for the same time interval. Both A. turcomanica and A. orientalis are known as late flowering almond species. Bayazit (2007) reported that the flowering date of $A$. turcomanica was 3-7 d later than those of $A$. orientalis suggesting a possible avoidance against late spring frosts as well.

Since, as A. orientalis and A. turcomanica, wild species of almond have advantages in almond breeding, genotypes were used to determine pollen production amount, pollen viability, and pollen germination features, which are important traits to determine self-fertile genotypes, genotypes with resistance to unfavorable soil conditions including high loam and rocky soil and dwarfing rootstock and breeding of late flowering almond genotypes.

\section{MATERIALS AND METHODS}

Pollen of selected almond species trees from Southeast Anatolia (Gaziantep and Şanliurfa province); A. orientalis ('Ori 1', 'Ori 4', ‘Ori 5', 'Ori 8', 'Ori 13', 'Ori 14', ‘Ori
B4'), A. turcomanica (Tur 6', 'Tur 10', 'Tur 11', 'Tur 15', 'Tur 5', 'Tur 7', 'Tur 8') and P. dulcis ('Nonpareil', 'Ferraduel', 'Tuono') were used in the experiment. The genotypes (A. orientalis and A.turcomanica) used in the experiment were collected according to Bayazit (2007). Genotypes of 'Ori 1', 'Ori 4', 'Ori 5', 'Ori 8', 'Ori 13', 'Ori 14' and 'Tur 6', 'Tur 10', 'Tur 11', 'Tur 15' were collected from Nizip district of Gaziantep, at the same way genotypes of 'Ori B4' and 'Tur 5', 'Tur 7', 'Tur 8' were collected from Birecik district of Şanliurfa. Collected genotypes were the natural populations grown of the region and they were not given any cultural applications. The age of orientalis genotypes were 10-29 $\mathrm{yr}$ and the ages of turcomanica genotypes were 10-17 yr. Almond cultivars with $10 \mathrm{yr}$ age of cultivated on seed rootstock were obtained from Pozantı Agricultural Experimental Station, Çukurova University, were also used in the experiment (Table 1).

Balloon staged flower of the almond genotypes were collected, anthers were extracted and they were stored at room temperature $\left(25^{\circ} \mathrm{C}\right)$ in $1 \mathrm{~d}$. Pollen viability and germination percentage tests were performed according to Eti (1990) method.

\section{Pollen viability tests}

The 2,3,5-triphenyltetrazolium chloride (TTC) and fluorescein diacetate (FDA) tests were used to determine the pollen viability rate of wild almond species and cultivars. In TTC test, $0.2 \mathrm{~g}$ triphenyltetrazolium chloride and $12 \mathrm{~g}$ sucrose were dissolved in $20 \mathrm{~mL}$ distilled water (Norton, 1966). One or two drops of TTC solution was put on a clean micro slide and pollen grains were sprinkled on these drops with a brush. Then, the drop was carefully covered by a cover glass without trapping air and kept for $2 \mathrm{~h}$ at ambient conditions. For this assay, two lamella for each genotypes and three regions of each lamella were investigated. Pollen grains were examined using a fluorescence microscope (Euromex Microscopes Holland,

Table 1. Average age and location of almond species.

\begin{tabular}{|c|c|c|c|c|c|}
\hline Genotype & County/City & $\begin{array}{c}\text { Average } \\
\text { age } \\
\text { (year) }\end{array}$ & Latitude & Longitude & $\begin{array}{c}\text { Eleva- } \\
\text { tion } \\
\text { (m.a.s.1.) }\end{array}$ \\
\hline Ori 1 & Nizip/Gaziantep & 12 & $37^{\circ} 03^{\prime} 37^{\prime \prime} \mathrm{N}$ & $37^{\circ} 29^{\prime} 34^{\prime \prime} \mathrm{E}$ & 786 \\
\hline Ori 4 & Nizip/Gaziantep & 29 & $37^{\circ} 03^{\prime} 37^{\prime \prime} \mathrm{N}$ & $37^{\circ} 29^{\prime} 34^{\prime \prime} \mathrm{E}$ & 786 \\
\hline Ori 5 & Nizip/Gaziantep & 18 & $37^{\circ} 03 ’ 38^{\prime \prime} \mathrm{N}$ & $37^{\circ} 29^{\prime} 32^{\prime \prime} \mathrm{E}$ & 786 \\
\hline Ori 8 & Nizip/Gaziantep & 23 & $37^{\circ} 03^{\prime} 38^{\prime \prime} \mathrm{N}$ & $37^{\circ} 29^{\prime} 31^{\prime \prime} \mathrm{E}$ & 786 \\
\hline Ori 13 & Nizip/Gaziantep & 20 & $37^{\circ} 03 ’ 39^{\prime \prime} \mathrm{N}$ & $37^{\circ} 37^{\prime} 26^{\prime \prime} \mathrm{E}$ & 845 \\
\hline Ori 14 & Nizip/Gaziantep & 20 & $37^{\circ} 03 ’ 40^{\prime \prime} \mathrm{N}$ & $37^{\circ} 37^{\prime} 25^{\prime \prime} \mathrm{E}$ & 844 \\
\hline Ori B4 & Birecik/Şanlıurfa & 19 & $37^{\circ} 00 ’ 34^{\prime \prime} \mathrm{N}$ & $37^{\circ} 59^{\prime} 49^{\prime \prime} \mathrm{E}$ & 385 \\
\hline Tur 6 & Nizip/Gaziantep & 12 & $37^{\circ} 03{ }^{\prime} 34^{\prime \prime} \mathrm{N}$ & $37^{\circ} 29^{\prime} 36^{\prime \prime} \mathrm{E}$ & 789 \\
\hline Tur 10 & Nizip/Gaziantep & 16 & $37^{\circ} 03 ’ 22^{\prime \prime} \mathrm{N}$ & 37³3'39”' E & 788 \\
\hline Tur 11 & Nizip/Gaziantep & 17 & $37^{\circ} 03{ }^{\prime} 38^{\prime \prime} \mathrm{N}$ & $37^{\circ} 37^{\prime} 28^{\prime \prime} \mathrm{E}$ & 846 \\
\hline Tur 15 & Nizip/Gaziantep & 16 & $37^{\circ} 03^{\prime} 41^{\prime \prime} \mathrm{N}$ & $37^{\circ} 37^{\prime} 24^{\prime \prime} \mathrm{E}$ & 842 \\
\hline Tur 5 & Birecik/Şanlıurfa & 10 & $37^{\circ} 00^{\prime} 27^{\prime \prime} \mathrm{N}$ & $37^{\circ} 59^{\prime} 40^{\prime \prime} \mathrm{E}$ & 379 \\
\hline Tur 7 & Birecik/Şanlıurfa & 13 & $37^{\circ} 03^{\prime} 34^{\prime \prime} \mathrm{N}$ & $37^{\circ} 58^{\prime} 34^{\prime \prime} \mathrm{E}$ & 382 \\
\hline Tur 8 & Birecik/Şanlıurfa & 16 & $37^{\circ} 03 ’ 34^{\prime \prime} \mathrm{N}$ & $37^{\circ} 58^{\prime} 33^{\prime \prime} \mathrm{E}$ & 381 \\
\hline Nonpareil & POZMER & 10 & $36^{\circ} 28^{\prime} 05^{\prime \prime} \mathrm{N}$ & $34^{\circ} 53^{\prime} 53^{\prime \prime} \mathrm{E}$ & 1050 \\
\hline Ferraduel & POZMER & 10 & $36^{\circ} 28^{\prime} 05^{\prime \prime} \mathrm{N}$ & $34^{\circ} 53^{\prime} 53^{\prime \prime} \mathrm{E}$ & 1050 \\
\hline Tuono & POZMER & 10 & $36^{\circ} 28^{\prime} 05^{\prime \prime} \mathrm{N}$ & $34^{\circ} 53^{\prime} 53^{\prime \prime} \mathrm{E}$ & 1050 \\
\hline
\end{tabular}

Ori: Amygdalus orientalis, Tur: Amygdalus turcomanica, POZMER: Pozantı Agricultural Research Center of Çukurova University. 
Arnhem, The Netherlands). The viability of pollen was scored according to staining level: pollen with dark red color as viable, with light red color as semi-viable and with yellowish-green color or colorless as non-viable.

In FDA test, $2 \mathrm{mg}$ fluorescent diacetate and $1.71 \mathrm{~g}$ sucrose were dissolved in $10 \mathrm{~mL}$ distilled water (HeslopHarrison and Heslop-Harrison, 1970) and the pollen was dusted. All pollen grains, which fluoresced brightly in a fluorescence microscope, were scored as viable.

\section{Pollen germination tests}

The pollen germination tests were conducted on Petri dishes with $1 \%$ agar medium containing $0,10,15$ and $20 \%$ sucrose (Eti, 1990). After the media within Petri dishes cool down to room temperature, pollen sowing was performed. For each genotype, two Petri dishes and six regions in each Petri were investigated using a fluorescence microscopy (Euromex Microscopes Holland), and percentages of germination were determined.

\section{Pollen production rate}

The following parameters were taken into consideration in determining the pollen production rate of the almond species: number of anthers per flower (AF); number of pollen grains per flower (PF); number of pollen grains per anther $(\mathrm{PA})=\mathrm{PF} / \mathrm{AF}$; percentage of well-developed pollen grains (DP).

Number of pollen grains per flower was determined using the hemacytometric method, as described by Eti (1990). The morphological homogeneity level of pollen was also tested by the same method. To obtain the average number of each component, 30 randomly selected flowers from each tree were collected. All the parameters given above for the flowers were counted and then the average number of the parameters of each almond species and cultivars was calculated.

Data were analyzed using SAS procedures (SAS Institute, 2005). The variables expressed as percentages were normalized by a root squared arcsine transformation. The means and standard deviations were calculated using the TABULATE procedure (SAS Institute, 2005). The General Linear Model (GLM) procedure was used to calculate ANOVA tables, where significant differences between means were separated by Tukey at $5 \%$.

\section{RESULTS AND DISCUSSION}

\section{Pollen viability}

The results of TTC and FDA tests (Table 2) showed that there were significant differences among the genotypes for pollen viability. The TTC test showed that pollen viability means of A. orientalis (82.8\%) and A. turcomanica $(84.1 \%)$ were higher than the cultivars $(76.6 \%)$. The FDA tests results showed that pollen viability of $P$. dulcis $(88.2 \%)$ species was higher than those of the wild and cultivated almond species.
Table 2. The percentage of pollen viability by 2,3,5-triphenyltetrazolium chloride (TTC) and fluorescein diacetate (FDA) tests in Amygdalus orientalis, A. turcomanica and Prunus dulcis genotypes.

\begin{tabular}{|c|c|c|c|c|c|}
\hline \multirow[b]{2}{*}{ Genotype } & \multicolumn{3}{|c|}{ TTC } & \multicolumn{2}{|c|}{ FDA } \\
\hline & Viable & $\begin{array}{l}\text { Semi- } \\
\text { Viable }\end{array}$ & $\begin{array}{c}\text { Non- } \\
\text { Viable }\end{array}$ & Viable & $\begin{array}{c}\text { Non- } \\
\text { Viable }\end{array}$ \\
\hline Ori 1 & $94.5 \mathrm{a}$ & $2.7 \mathrm{de}$ & $2.8 \mathrm{e}$ & $46.4 f$ & $53.6 \mathrm{a}$ \\
\hline Ori 4 & $80.8 b-f$ & $2.8 \mathrm{de}$ & $16.4 \mathrm{a}-\mathrm{c}$ & $45.9 f$ & $54.1 \mathrm{a}$ \\
\hline Ori 5 & $83.4 \mathrm{a}-\mathrm{e}$ & $9.1 \mathrm{bc}$ & $7.5 \mathrm{c}-\mathrm{e}$ & $48.7 f$ & $51.3 \mathrm{a}$ \\
\hline Ori 8 & $66.7 \mathrm{~g}$ & 13.9ab & $19.4 \mathrm{ab}$ & $51.8 \mathrm{~d}-\mathrm{f}$ & $48.2 \mathrm{a}-\mathrm{c}$ \\
\hline Ori 13 & $88.7 a-c$ & $7.9 \mathrm{~cd}$ & $3.4 \mathrm{de}$ & $72.0 \mathrm{bc}$ & $28.0 \mathrm{de}$ \\
\hline Ori 14 & $69.5 \mathrm{fg}$ & $10.0 \mathrm{bc}$ & $20.5 a$ & $40.9 f$ & $59.2 \mathrm{a}$ \\
\hline Ori B4 & $87.7 \mathrm{a}-\mathrm{c}$ & $5.0 \mathrm{c}-\mathrm{e}$ & $7.3 \mathrm{c}-\mathrm{e}$ & $69.9 b c$ & $30.1 \mathrm{de}$ \\
\hline Tur 6 & $88.4 \mathrm{a}-\mathrm{c}$ & $2.3 \mathrm{e}$ & $9.3 \mathrm{~b}-\mathrm{e}$ & $50.6 \mathrm{ef}$ & 49.4ab \\
\hline Tur 10 & $81.9 \mathrm{~b}-\mathrm{e}$ & $7.0 \mathrm{c}-\mathrm{e}$ & $11.0 \mathrm{a}-\mathrm{e}$ & $62.9 c-e$ & $37.2 b-d$ \\
\hline Tur 11 & $78.0 \mathrm{c}-\mathrm{g}$ & $9.9 \mathrm{bc}$ & $12.1 \mathrm{a}-\mathrm{e}$ & $51.9 \mathrm{~d}-\mathrm{f}$ & $48.1 \mathrm{a}-\mathrm{c}$ \\
\hline Tur 15 & $86.2 \mathrm{a}-\mathrm{d}$ & $7.0 \mathrm{c}-\mathrm{e}$ & $6.8 \mathrm{c}-\mathrm{e}$ & $50.3 \mathrm{ef}$ & 49.7ab \\
\hline Tur 5 & $92.5 \mathrm{ab}$ & $5.3 \mathrm{c}-\mathrm{e}$ & $2.3 \mathrm{e}$ & $65.5 \mathrm{~cd}$ & $34.6 \mathrm{~cd}$ \\
\hline Tur 7 & $79.0 c-f$ & $7.6 c-e$ & $13.4 \mathrm{a}-\mathrm{d}$ & $42.2 \mathrm{f}$ & $57.8 \mathrm{a}$ \\
\hline Tur 8 & $83.0 \mathrm{a}-\mathrm{e}$ & $6.9 c-e$ & 10.1a-e & $42.6 f$ & $57.4 \mathrm{a}$ \\
\hline Nonpareil & $75.4 \mathrm{~d}-\mathrm{g}$ & $16.2 \mathrm{a}$ & $8.5 \mathrm{c}-\mathrm{e}$ & $90.2 \mathrm{a}$ & $9.8 \mathrm{f}$ \\
\hline Ferraduel & $73.6 \mathrm{e}-\mathrm{g}$ & 14.6ab & $11.8 \mathrm{a}-\mathrm{e}$ & $82.4 \mathrm{ab}$ & 17.6ef \\
\hline Tuono & $80.9 b-f$ & $6.9 c-e$ & $12.2 \mathrm{a}-\mathrm{e}$ & $91.9 \mathrm{a}$ & $8.1 \mathrm{f}$ \\
\hline $\mathrm{HSD}_{0.05}$ & 12.0 & 5.5 & 10.5 & 13.8 & 13.8 \\
\hline A. orientalis & 82.8 & 7.3 & 11.1 & 53.6 & 46.4 \\
\hline A. turcomanica & 84.1 & 6.6 & 9.3 & 52.3 & 47.7 \\
\hline P. dulcis & 76.6 & 12.5 & 10.8 & 88.2 & 11.8 \\
\hline Mean & 81.2 & 8.8 & 10.4 & 64.7 & 35.3 \\
\hline
\end{tabular}

Ori: Amygdalus orientalis, Tur: Amygdalus turcomanica.

In TTC test, the highest rate of viability (94.5\%) was obtained from genotype 'Ori 1' and the lowest germination rate of $66.7 \%$ was obtained from genotype 'Ori 8'. In TTC test, the percentage of semi-lived pollen of A. orientalis and A.turcomanica species were found close to each other ( $7.3 \%$ and $6.6 \%$, respectively), whereas the other cultivated almond varieties showed a value bigger than $12.5 \%$. Non-viable pollen rates did not differ much among the three almond species.

The FDA test results showed that mean pollen viability of A. orientalis (53.6\%) and A. turcomanica $(52.3 \%)$ were close to each other while pollen viability of cultivated almond species was $88.2 \%$. The highest rate of pollen viability in the FDA test results was obtained from 'Nonpareil' (90.2\%) and 'Tuono' (91.9\%) cultivars. The lowest value, as similar to TTC test, belongs to 'Ori 14' $(40.2 \%)$. The highest viability rates in $A$. orientalis almond type was $72.0 \%$ for 'Ori 13', and in A. turcomanica almond type was $65.5 \%$ for 'Tur 5 ' in FDA. Eti et al. (1993) have reported that pollen viability of some almond genotypes vary year by year, and TTC test results showed the highest rates of 58.3\% in 1988 and rates of $82.2 \%$ in 1990 . The FDA viability test results, $37.9-71.6 \%$ (1989 year) with 29.5-91.2\% (1990 year), have been reported for different almond species. Tosun et al. (2007) determined that pollen viability of almond genotypes values ranged from 71.8-85.9\%. Results of this research showed that the values of $A$. orientalis, $A$. turcomanica and the cultivars were higher than those of Eti et al. (1993) but similar to those of Tosun et al. (2007). Viability values of $P$. dulcis cultivars in many researches were similar to values reported by Eti et al. (1993) and Tosun et al. (2007). 


\section{Pollen germination}

Pollen germination percentages (Table 3 ) varied depending on species, genotypes and sucrose dose. Mean pollen germination percentages of $A$. orientalis almond species in $10 \%$ sucrose medium was $53.7 \%$, in $15 \%$ sucrose medium was $29.5 \%$, and in $20 \%$ sucrose medium was $36 \%$, respectively. A.turcomanica species showed $53.7 \%$, $38.3 \%$ and $16.2 \%$ in the same media. Pollen germination percentages of A. orientalis and A. turcomanica species were higher in the medium containing $10 \%$ sucrose (Table 2). However, $P$.dulcis type showed the highest germination percentages $(77.1 \%)$ medium containing $15 \%$ sucrose. Eti (1991) reported that diverse fruits species' and cultivars' pollen grains showed some variation in germination percentages in different sucrose concentrations. Eti et al. (1996) reported that the most suitable media for pollen germination of some almond cultivars or ecotypes is $15 \%$ sucrose solution. However, some almond genotypes can show better germination percentages in $10 \%$ and $20 \%$ sucrose solution, respectively.

Our results were similar to those reported in the previous studies that most of the almond genotypes showed the best pollen germination percentages within $15 \%$ sucrose solution. Meanwhile, A. orientalis and A. turcomanica genotypes showed better pollen germination percentages. These differences may be attributed to the environmental factors (higher temperature, lower humidity, and higher salinity, and UV rays) as well as humidity, pressure, temperature, and $\mathrm{pH}$ of the media (Asif et al., 1983; Eti, 1991; Ferri et al., 2008).

In the agar test (1\% agar, $10 \%$ sucrose), the highest pollen germination rate was obtained from ' Ori 5' $(88.5 \%)$, which was followed by 'Tuono' (85.8\%), 'Ori 13' (86.4\%), 'Nonpareil' (76.3\%) and 'Tur 6' (76.3\%). 'Ori 4', and 'Ori 14' had the lowest germination percentages (6.9 and

Table 3. The germination percentages of pollen by agar in Petri dish in Amygdalus orientalis, A.turcomanica and Prunus dulcis genotypes.

\begin{tabular}{lcccc}
\hline & \multicolumn{4}{c}{ Sucrose concentration $(\%)$} \\
\cline { 2 - 5 } Genotype & 0 & 10 & 15 & 20 \\
\hline Ori 1 & 0.0 & $71.5 \mathrm{bc}$ & $66.9 \mathrm{c}$ & $71.8 \mathrm{ab}$ \\
Ori 4 & 0.0 & $6.9 \mathrm{~h}$ & $5.3 \mathrm{~g}$ & $5.9 \mathrm{gh}$ \\
Ori 5 & 0.0 & $88.5 \mathrm{a}$ & $83.9 \mathrm{a}$ & $70.0 \mathrm{ab}$ \\
Ori 8 & 0.0 & $65.5 \mathrm{~cd}$ & $46.4 \mathrm{de}$ & $34.9 \mathrm{~d}$ \\
Ori 13 & 0.0 & $86.4 \mathrm{ab}$ & $2.1 \mathrm{~g}$ & $51.7 \mathrm{c}$ \\
Ori 14 & 0.0 & $2.4 \mathrm{~h}$ & $2.1 \mathrm{~g}$ & $1.6 \mathrm{~h}$ \\
Ori B4 & 0.0 & $54.6 \mathrm{def}$ & $0.1 \mathrm{~g}$ & $16.1 \mathrm{efg}$ \\
Tur 6 & 0.0 & $76.3 \mathrm{abc}$ & $48.6 \mathrm{de}$ & $19.4 \mathrm{ef}$ \\
Tur 10 & 0.0 & $48.2 \mathrm{fg}$ & $22.3 \mathrm{f}$ & $12.4 \mathrm{e}-\mathrm{h}$ \\
Tur 11 & 0.0 & $48.5 \mathrm{efg}$ & $39.4 \mathrm{e}$ & $0.0 \mathrm{~h}$ \\
Tur 15 & 0.0 & $50.8 \mathrm{~d}-\mathrm{g}$ & $47.7 \mathrm{de}$ & $28.9 \mathrm{de}$ \\
Tur 5 & 0.0 & $62.0 \mathrm{c}-\mathrm{f}$ & $53.8 \mathrm{~d}$ & $33.3 \mathrm{~d}$ \\
Tur 7 & 0.0 & $50.8 \mathrm{~d}-\mathrm{g}$ & $28.2 \mathrm{f}$ & $9.6 \mathrm{fgh}$ \\
Tur 8 & 0.0 & $37.9 \mathrm{~g}$ & $27.7 \mathrm{f}$ & $9.5 \mathrm{fgh}$ \\
Nonpareil & 0.0 & $76.3 \mathrm{abc}$ & $77.2 \mathrm{ab}$ & $78.9 \mathrm{a}$ \\
Ferraduel & 0.0 & $64.8 \mathrm{cde}$ & $70.1 \mathrm{bc}$ & $60.4 \mathrm{bc}$ \\
Tuono & 0.0 & $85.8 \mathrm{ab}$ & $84.2 \mathrm{a}$ & $81.3 \mathrm{a}$ \\
HSD & & 16.6 & 10.1 & 13.2 \\
A. orientalis & & 53.7 & 29.5 & 36.0 \\
A. turcomanica & & 53.7 & 38.3 & 16.2 \\
P.dulcis & & 75.6 & 77.1 & 73.5 \\
Mean & & 61.0 & 48.3 & 41.9 \\
\hline Or: Amyg & & & \\
\hline
\end{tabular}

Ori: Amygdalus orientalis, Tur: Amygdalus turcomanica.
$2.4 \%$, respectively). Dicenta et al. (2002) reported that pollen germination percentages of self pollinated almond species ranged 36.0-74.0\%. Sharafi et al. (2010) indicated that pollen germination percentages of almond genotypes ranged $35.0-82.0 \%$ in $15 \%$ sucrose containing media. Our findings were generally similar to those results. Observed differences may be attributed to the effects of almond species on germination percentages.

When the pollen viability and germination values are considered, it can be concluded that these genotypes can be used as pollinators for those almond species that bloom in the same period. It is worth to point out that the high germination rates found in vitro do not always indicate a good outcome in vivo pollination for any cross combinations. To be a good pollinator, the amount of pollen of variety should be high, as well as the higher ability and germination percentage has great importance (Stosser, 1984; Eti, 1990). The findings of our study emphasized the potential importance of investigated wild almond species for in vivo pollination study.

\section{Pollen production}

The number of the anther within each flower was dependent on almond species and genotypes, and the anther numbers per flower were significantly different (Table 4). The value of cultivated almond species was 29.0 anthers per flower. Number of anthers per flower for A. orientalis almond species were ranged 15.6 ('Ori 5')26.6 ('GA 13') with a mean of 21.0 anthers per flower.

Number of anthers per flower of A. turcomanica species ranged 10.2 ('Tur 7')-18.0 ('Tur 11') and the mean value was 13.9. Anther number per flower of the A. turcomanica species was lower than the other two species used in the experiment. Godini (1981) reported that the anther number per flower of the cultivated almond cultivars ranged 20.4-37.2.

Pollen numbers within an anther varied depending on almond species and genotypes. Pollen number per anther of A. orientalis species ranged 1623 ('Ori 8')-2669 ('Ori 4 ') with an average of 2185 . Pollen number per anther of A. turcomanica species ranged 775 ('Tur 6')-3220 ('Tur 5') and the mean value for pollen number was 1932. Pollen number of A. orientalis and A. turcomanica species was lower than the cultivated variety(ies) (1146) used in the experiment. Godini (1981) reported that the pollen number of some almond cultivars was specific to years and the number ranged from 1099 to 1787. Previous studies have shown that the pollen number per anther of apricot ranged 1574-3757 (Mahanoglu et al., 1995) and 1211-3042 (Asma, 2008) of cornelian cherry ranged 1823418 (Pirlak and Güleryüz, 2005). Our results are similar to these previously published stone fruit species.

The number of pollen grains per flower within almond genotypes used in the experiment was specific to genotypes and species and thus, they were significantly different (Table 4). The mean pollen grain number per 
Table 4. The values of pollen production components in Amygdalus orientalis, A.turcomanica and Prunus dulcis genotypes.

\begin{tabular}{|c|c|c|c|c|}
\hline Genotype & $\begin{array}{c}\text { Anther } \\
\text { number/flower }\end{array}$ & $\begin{array}{c}\text { Pollen } \\
\text { number/flower }\end{array}$ & $\begin{array}{c}\text { Pollen } \\
\text { number/flower }\end{array}$ & $\begin{array}{l}\text { Morphological } \\
\text { homogeneity } \\
(\%)\end{array}$ \\
\hline Ori 1 & 18.3d-h & $2185 a-e$ & 39 850a-e & $88.6 \mathrm{a}-\mathrm{c}$ \\
\hline Ori 4 & $22.4 c-f$ & 2019a-f & $45804 a-d$ & $82.3 \mathrm{a}-\mathrm{d}$ \\
\hline Ori 5 & $15.6 f-1$ & $2536 a-c$ & $39376 a-f$ & $86.4 a-c$ \\
\hline Ori 8 & $20.8 c-f$ & $1623 b-f$ & 33 824b-f & $87.7 a-c$ \\
\hline Ori 13 & 26.6a-c & 2486a-d & $66075 a$ & $96.3 \mathrm{a}$ \\
\hline Ori 14 & $24.5 b-d$ & $1937 a-f$ & $47314 a-c$ & $81.3 b-d$ \\
\hline Ori B4 & $19.0 \mathrm{~d}-\mathrm{g}$ & $2669 a-c$ & $50556 \mathrm{ab}$ & $83.3 \mathrm{a}-\mathrm{d}$ \\
\hline Tur 6 & $16.5 \mathrm{e}-1$ & $775 \mathrm{ef}$ & $12726 f$ & $83.4 \mathrm{a}-\mathrm{d}$ \\
\hline Tur 10 & $12.0 g_{-1}$ & $1345 c-f$ & $15963 \mathrm{ef}$ & $78.1 \mathrm{~cd}$ \\
\hline Tur 11 & $18.0 \mathrm{~d}-\mathrm{h}$ & $1477 \mathrm{c}-\mathrm{f}$ & 19 209d-f & $65.2 \mathrm{e}$ \\
\hline Tur 15 & 17.6d-h & $3022 a b$ & $55298 \mathrm{ab}$ & $94.0 \mathrm{ab}$ \\
\hline Tur 5 & $11.2 \mathrm{~h} 1$ & $3220 a$ & $36008 b-f$ & $69.3 \mathrm{de}$ \\
\hline Tur 7 & 10.21 & 2088a-f & $21392 c-f$ & $86.4 a-c$ \\
\hline Tur 8 & $11.7 \mathrm{~g}-1$ & $1595 b-f$ & $18305 \mathrm{ef}$ & $79.5 \mathrm{c}-\mathrm{e}$ \\
\hline Nonpareil & $30.1 \mathrm{ab}$ & $710 f$ & $21365 c-f$ & $77.8 \mathrm{c}-\mathrm{e}$ \\
\hline Ferraduel & $23.4 \mathrm{~b}-\mathrm{e}$ & $1656 b-f$ & $36704 b-f$ & $88.2 \mathrm{a}-\mathrm{c}$ \\
\hline Tuono & $33.6 \mathrm{a}$ & $1072 d-f$ & $35935 b-f$ & $87.1 \mathrm{a}-\mathrm{c}$ \\
\hline $\mathrm{HSD}_{0.05}$ & 7.4 & 1140 & 26817 & 14.5 \\
\hline A. orientalis & 21.0 & 2185 & 46114 & 86.6 \\
\hline A. turcomanica & a 13.9 & 1932 & 25557 & 79.4 \\
\hline P. dulcis & 29.0 & 1146 & 31335 & 84.4 \\
\hline Mean & 17.4 & 1754 & 34335 & 83.4 \\
\hline
\end{tabular}

Ori: Amygdalus orientalis, Tur: Amygdalus turcomanica.

flower of the cultivated almond species was 31335 . Pollen grain number per flower of $A$. orientalis species ranged 33824 ('Ori 8')-66 075 ('Ori 13') and the average value was 46 114. Pollen number per flower of A. turcomanica species ranged 12726 ('Tur 6')-55 298 ('Tur 15') and the average value was 25557 . Godini (1981) reported that the pollen number of some almond cultivars' flower ranged from 36960 to 56776 whereas Traynor (2001) found a range of $42000-67000$. The value for pollen grain numbers/flower of the three species used in our experiment was in agreement with the previous works. In terms of pollen amount within a flower, within anther and morphological homogeneity $A$.orientalis had significantly higher values than the other two almond species (Table 4). Pollen viability, pollen germination and pollen production amount of A. orientalis and A. turcomanica almond species were close to cultivated almond species. The data suggested that these species were as important as cultivated species in terms of pollen production amount and pollen quality. Although, pollen viability of 'Ori 4' and 'Ori 14' genotypes within A. orientalis species were higher than $70 \%$, germination percentages lower than $7 \%$ showed that these genotypes were not suitable for almond hybridization works.

\section{CONCLUSIONS}

A vast number of fruit research have recently emphasized the importance of the fruit genetic recourses. This resources not only needs to be not collected, characterized and maintain, but also should be utilized in plant breeding programs. Similar to other fruit species, the almond breeders have been concentrated on the higher yielding and quality genotypes; and this have been resulted in production of relatively few cultivars worldwide. However, this approach is not a powerful strategy for adaptability to undesirable conditions. To cope with this, more almond species should be utilized in the almond breeding programs and the genetic base should be broadened. The wild almond species of Turkey are present in the unfavorable ecological conditions such as high and low temperatures, low precipitation, high saltiness, high pest and disease pressure, therefore, it seems a plausible option to search for resistance against these stress factor among the wild almond genotypes from several species. Boarding the genetic bases of almond is a beneficial strategy for many other reasons including a possible resistance to the stress factor that may arise in the future. Findings of our experiment showed that pollen of genotypes within A. orientalis and A. turcomanica almond species could be used for breeding and improving cold-resistance and self-fertile almond cultivars. It is important that before beginning any hybridization work, pollen viability should be determined first, and then the hybridization studies can be performed. In this way, efficiency of hybridization program of almond species can be increased. Taken together, A. orientalis and A. turcomanica species offer a great potential for the almond improvement. Therefore, crossing studies between these wild species and the cultivated almonds will be initiated for almond breeding programs.

Comparación de producción y características de calidad del polen de especies de almendro cultivadas y silvestres. Hay varias especies de almendros silvestres en Turquía incluidas Amygdalus orientalis (Mill.), Amygdalus turcomanica (Lincz.), Amygdalus fenzliana (Fritsch) Lipsky, Amygdalus trichamygdalus (Hand.Mazz.) Woronow, Amygdalus arabica (Olivier), y Amygdalus webbii (Spach). Estas especies ofrecen un gran valor para mejoramiento del almendro; se estudió la viabilidad del polen, tasa de germinación, y producción de polen para siete genotipos de A.orientalis y siete genotipos de $A$. turcomanica cultivados en condiciones naturales en el sudeste de Anatolia (Gaziantep and Şanlıurfa provinces, Turkey). También se estudiaron cultivares de almendros (Prunus dulcis [Mill.] D.A. Webb) obtenidos desde Pozant1 Agricultural Experimental Station, Universidad de Çukurova. Las viabilidades de polen de los diversos genotipos se determinaron por las pruebas 2,3,5-trifeniltetrazolium cloruro (TTC) y fluoresceína diacetato (FDA). Las tasas de germinación de polen se establecieron en condiciones de placas Petri (1\% agar + $0,10,15$, y $20 \%$ sucrosa) mientras la producción de polen se estimó con métodos hemocitométricos. Las tasas de viabilidad de polen fueron cercanas entre ambos métodos para los genotipos de A. orientalis y A. turcomanica. Las tasas de germinación de polen fueron dependientes del contenido de sucrosa y del genotipo. Los cultivares mostraron tasas de germinación de polen similares en todas las concentraciones de sucrosa mientras el polen de 
los genotipos A. orientalis y A. turcomanica mostraron mayores tasas de germinación en $10 \%$ sucrosa. El número de anteras por flor fue mayor en los cultivares mientras el número de granos de polen fue menor en otras especies de almendro. Mientras el número de granos de polen por flor fue relativamente alto en genotipos de $A$. orientalis, la calidad del polen fue alta en las tres especies en investigación. Los resultados sugirieron que estas dos especies, A. orientalis y A. turcomanica, podrían ser usadas para futuros programas de mejoramiento de almendros.

Palabras clave: Amygdalus orientalis, Amygdalus turcomanica, Prunus dulcis, polen, germinación.

\section{LITERATURE CITED}

Asif, M.A., A.O. Al-Tahir, and A.F. Farah. 1983. The effects of some chemicals and growth substances on pollen germination and tube growth of date palm. HortScience 18:479-480.

Asma, B.M. 2008. Determination of pollen viability, germination ratios and morphology of eight apricot genotypes. African Journal of Biotechnology 7:4269-4273.

Atll, H.S. 2008. Determination of rootstocks characterizations of Amygdalus orientalis Mill, types. Publication $\mathrm{N}^{\circ} 37.14 \mathrm{p}$. Republic of Turkey, Ministry of Agriculture and Rural Affairs, General Directorate of Agricultural Research.

Bayazit, S. 2007. Phenological, morphological, pomological and molecular characteristics of the wild almond genotypes collected from different ecotypes of Turkey. PhD Thesis. University of Çukurova, Department of Horticulture, Institute of Natural and Applied Sciences, Adana, Turkey.

Bayazit, S., and A.B. Küden. 2007. Morphological characteristics of the wild almond genotypes collected from different ecotypes of Turkey. p. 707-711. $5^{\text {th }}$ International Horticultural Congress, Erzurum, Turkey. 4-7 September.

Browicz, K., and D. Zohary. 1996. The genus Amygdalus L. (Rosaceae) species relationships, distribution and evolution under domestication. Genetic Resources Crop Evolution 43:229-247.

Denisov, V.P. 1988. Almond genetic resources in the USSR and their use in production and breeding. Acta Horticulturae 244:299-306

Dicenta, F., E. Ortega, J.A. Canovas, and J. Egea. 2002. Selfpollination vs. cross-pollination in almond: pollen tube growth, fruit set and fruit characteristics. Plant Breeding 121:163-167.

Eti, S. 1990. A practical method used to determine the amount of pollen. Cukurova University, Journal of Agricultural Faculty 5:49-58.

Eti, S. 1991. Determining of the capabilities of pollen viability and germination in some fruit species and cultivars via in vitro tests. Cukurova University, Journal of Agricultural Faculty 6:69-80.

Eti, S., S. Paydaş, A.B. Küden, N. Kaşka, Ş. Kurnaz, and M. Ilgin. 1993. Researches on fertilization biology and embryo development of some almond cultivars grown in the Çukurova Conditions. TOAG Project $\mathrm{N}^{\circ} 675$, Adana, Turkey.
Eti, S., S. Paydaş, A.B. Küden, N. Kaşka, S. Kurnaz, and M. Ilgin. 1996. Researches on pollen viability, the ability to pollen germination, amount of pollen, and pollen tube growth of some selected almond types and Texas cultivar in Adana ecological conditions. Turkish Journal of Agriculture and Forestry 20:521527.

Ferri, A., E. Giordani, E. Padula, and E. Bellini. 2008. Viability and in vitro germinability of pollen grains of olive cultivars and advanced selections obtained in Italy. Advances in Horticultural Sciences 22:116-122.

Godini, A. 1981. Couting pollen grains of some almond cultivars by means of a haemocytometer. p. 83-86. In GREMPA Colloque 1980, Paris. CIHEAM-Options Mediterranéennes Série Etudes 1981-I, Institut Agronomique Méditerranéen de Zaragoza (IAMZ).

Gradziel, T.M., P. Martínez-Gómez, F. Dicenta, and D.E. Kester. 2001. The utilization of related almond species for almond variety improvement. Journal of the American Pomological Society 55:100-109.

Heslop-Harrıson, J., and Y. Heslop-Harrıson. 1970. Evaluation of pollen viability by enzymatically induced fluorescence. Intra cellular hydrolysis of fluorescein diacetate. Stain Technology 45:115-120.

Kester, D.E., and T.M. Gradziel. 1996. Almonds. p. 1-97. In Moore, J.N., and J. Janick (eds.) Fruit breeding. John Wiley \& Sons, New York, USA.

Kester, D.E., T.M. Gradziel, and C. Grasselly. 1990. Almond (Prunus). p. 701-758. In Moore, J.N., and I.R. Balligton (eds.) Genetic resources of temperate fruits and nut crops. International Society Horticultural Science, Wageningen, The Netherlands.

Küden, A.B. 1997. Almond germplasm and production in Turkey and the future of almonds in the GAP area. Acta Horticulturae 470:29-37.

Mahanoglu, G., S. Eti, and N. Kaşka. 1995. Correlations between pollen quality, pollen production and pollen tube growth of some early ripening apricot culture. Acta Horticulturae 384:391-396.

Norton, J.D. 1966. Testing of plum pollen viability with tetrazolium salts. Proceedings of the American Society for Horticultural Science 89:132-134.

Prrlak, L., and M. Güleryüz. 2005. Determination of pollen quality and quantity in Cornelian cherry (Cornus mass L.) Bangladesh Journal of Botany 34:1-6.

SAS Institute. 2005. SAS user guide; SAS/STAT, version 6. SAS Institute, Cary, North Carolina, USA.

Sharafi, Y., M. Karimi, and M. Ghorbanifar. 2010. Study of pollen tube growth, cross-compatibility and fruit set in some almond genotypes. African Journal of Plant Science 4:135-137.

Stosser, R. 1984. Untersuchungen über die Befruchtungsbiologische und Pollenproduktion İnnerhalb der Gruppe $P$. domestica. Erwerbsobstbau 26:1110-1115

Tosun, F.S., A. Yildırım, and F. Koyuncu. 2007. Studies on the pollination biology of some selected almond genotypes. 1 . Performance of pollen. p. 304-308. $5^{\text {th }}$ National Horticultural Congress, Erzurum, Turkey. 4-7 September.

Traynor, J. 2001. Evaluating pollen production of plants (with sample calculations for almonds). American Bee Journal, Chicago, Illinois, USA. Available at http://www.beesource.com/point-ofview/joe-traynor/evaluating-pollen-production-of-plants-withsample-calculations-for-almonds/ (accessed 30 June 2011). 